\title{
O comércio intra-setorial e suas implicações para a economia cearense
}

\author{
Gisela Maria Prata Avelino ${ }^{1}$ \\ Rosemeiry Melo Carvalho ${ }^{2}$ \\ Luíz Artur Clemente da Silva ${ }^{3}$
}

Resumo: Neste trabalho, analisou-se a participação do comércio intra-setorial nas exportações do estado do Ceará e os seus impactos sobre as principais variáveis econômicas durante o período de 1996 a 2004. Inicialmente, foi identificada a intensidade desse tipo de transação comercial, com base no índice proposto por Grubel e Lloyd (1975). A seguir, foi analisada a sua contribuição para o fluxo total de mercadorias comercializadas internacionalmente, com base na metodologia proposta por Menon e Dixon (1996). Os resultados obtidos mostraram que o comércio intra-setorial tem uma pequena participação no comércio total e que, embora alguns produtos primários e minerais participem desse tipo de comércio, as manufaturas são os principais produtos. Em relação aos seus impactos sobre as principais variáveis econômicas, verificou-se que o comércio intra-setorial tem efeitos positivos sobre o emprego, porém sua intensificação pode provocar aumentos no grau de concentração da pauta de exportações e no nível de concentração de renda enquanto reduz o grau de abertura comercial do estado do Ceará.

Palavras-chaves: comércio internacional, produtos diferenciados, comércio intra-setorial.

Abstract: This study aimed at the participation of intra-sectorial commerce of export results in Ceara state and its impacts on main economic variables from 1996 to 2004. The

\footnotetext{
${ }^{1}$ Mestre em Economia Rural, Universidade Federal do Ceará (UFC). E-mail: gisela_prata@yahoo.com.br

${ }^{2}$ Doutora em Economia, Professora do Departamento de Economia Agrícola. Bolsista do Programa de Educação Tutoria (PET). Universidade Federal do Ceará (UFC). E-mail: rmelo@ufc.br

${ }^{3}$ Doutor em Economia, Professor do Departamento de Economia Agrícola da Universidade Federal do Ceará (UFC). E-mail: artur@ufc.br
} 
intensity of this type of commercial transactions was identified, based on the Index considered for Grubel and Lloyd (1975). Consequently, it was analyzed its contribution for the total of internationally commercialized merchandises, based on methodology proposed for Menon and Dixon (1996). The analysis of the data show that intra-sectorial commerce has a small contribution at total commerce results and, despite some primary products and mineral participate, manufactures are main products. Regarding impacts on main economic variable, it was verified that the intra-sectorial commerce has positive effect on the generation of new jobs. However, its intensification can provoke increases in the concentration of export guideline and in the income level while reduces the degree of commercial aperture of Ceara state.

Key-words: international trade, differentiated products, intra-industry trade.

Classificação JEL: F10, O24, L17.

\section{Introdução}

Nos últimos anos, os trabalhos empíricos sobre comércio internacional têm evidenciado um incremento das exportações e importações entre países, ou grupos de países, de mercadorias pertencentes ao mesmo segmento industrial, o qual foi denominado de comércio intra-indústria ou intra-setorial. Entretanto, esse padrão não é consistente com a teoria tradicional, cujas hipóteses básicas fundamentam o comércio interindustrial ou intersetorial.

Durante as décadas de 1970 e 1980, muitos trabalhos surgiram com o objetivo de explicar o comércio intra-setorial. Alguns economistas procuraram justificar esse tipo de intercâmbio como resultado das agregações que são feitas nas estatísticas"; outros o atribuem ao comportamento dos consumidores de cada país, às estratégias das empresas produtoras e à existência de diferenciação vertical ou horizontal dos produtos.

Em termos geográficos, a incidência de comércio intra-setorial ocorre geralmente entre países industrializados em função, principalmente, das semelhanças nas dotações dos fatores e nos níveis de renda. Todavia, os processos de integração regional também criam condições favoráveis para esse tipo de intercâmbio (BAUMANN, 1998).

Deve-se ressaltar, contudo, que os dois tipos de comércio - intra-setorial e intersetorial - podem ocorrer simultaneamente. De modo que, no comércio intersetorial, prevalece a teoria de Heckscher-Ohlin, em que a especialização está

${ }^{4}$ Em geral, quanto maior for a agregação dos dados utilizados sobre comércio, maiores serão as evidências do comércio intra-setorial, porém, estudos empíricos mostram a existência desse tipo de comércio, mesmo considerando desagregações razoavelmente grandes (Grubel e Lloyd, 1975). 
baseada na dotação de fatores em cada um dos países, enquanto que, no comércio intra-setorial, a comercialização ocorre mesmo que a dotação de fatores seja semelhante entre dois países. Nesse caso, esse tipo de comércio fundamenta-se, principalmente, na existência de economias de escala, concorrência imperfeita e diferenciação dos produtos.

Os principais argumentos favoráveis ao comércio intra-setorial são: primeiro, quanto maior for o intercâmbio intra-setorial, menores serão os custos de ajuste da estrutura produtiva nacional em resposta a variações do comércio externo; segundo, quanto maior for a complementação produtiva entre os países, menor será a probabilidade de imposição de barreiras comerciais às importações.

Uma outra fonte de incentivo a esse padrão de comércio refere-se à possibilidade de especialização das economias na produção de um menor número de bens, porém o tamanho do mercado limita o grau de especialização. Assim, o livre comércio pode possibilitar o aprofundamento da divisão do trabalho com obtenção de maiores ganhos de eficiência, produtividade e competitividade no mercado internacional, garantindo o acesso dos consumidores a uma maior variedade de bens com ganhos reais de bem-estar.

$\mathrm{Na}$ economia brasileira, o comércio intra-setorial vem apresentando uma tendência crescente ao longo dos anos, todavia, algumas evidências empíricas, tais como as obtidas por Oliveira (1986), Lerda (1988), Albuquerque e Fernandes (1999) e Hidalgo (1993), mostram que esse padrão de trocas é mais freqüente nos grupos de produtos manufaturados, os quais são mais diferenciados.

No entanto, Hidalgo (1998) constatou que, no Nordeste do Brasil, o comércio intra-setorial não é um privilégio apenas dos produtos manufaturados. Nesse sentido, ele pode ser visto com certo otimismo por parte das regiões semi-industrializadas, abundantes em trabalho e escassas em capital.

Desse modo, neste estudo, pretende-se analisar a participação do comércio intra-setorial no comércio exterior do estado do Ceará para o período compreendido entre 1996 e 2004. Especificamente, pretende-se analisar sua evolução e a sua influência sobre importantes variáveis macroeconômicas tais como, o desemprego, a concentração de renda, a abertura comercial, o grau de concentração da pauta de exportações e o grau de industrialização do estado. Espera-se, com os resultados da pesquisa, contribuir para a fundamentação e definição de melhores estratégias de inserção e políticas comerciais para o Ceará.

Além desta seção introdutória, este estudo apresenta mais quatro seções. A seção dois mostra a evolução da teoria de comércio internacional; na seção três estão definidas as variáveis e as fontes dos dados empregados neste trabalho e também são apresentados, de forma detalhada, os métodos utilizados para analisar o comércio intra-setorial e sua influência sobre importantes indicadores econômicos do Ceará. A análise dos resultados encontra-se na seção quatro e as conclusões, na cinco. 


\section{Referencial Teórico}

A teoria do comércio internacional tenta responder questões fundamentais referentes aos fatores que determinam o comércio entre os países e os possíveis benefícios que podem ser obtidos a partir desse processo.

A busca por uma boa teoria é anterior ao nascimento da Economia como disciplina formalizada, o que para muitos acontece com a publicação de The Wealth of Nations de Adam Smith em 1776.

Nos séculos XVII e XVIII, acreditava-se que a riqueza das nações era determinada pelo seu estoque de moeda (metais preciosos) e que o comércio era o meio para aumentá-la. As idéias defendidas, durante essa época, ficaram conhecidas como "Mercantilismo".

$\mathrm{Na}$ visão mercantilista, a única estratégia compatível com o aumento da riqueza e do poder era a adoção de uma política comercial essencialmente protecionista e nacionalista, incentivando as exportações e desestimulando as importações. De modo que, não se admitia a possibilidade de obtenção de ganhos simultâneos para o conjunto de países envolvidos no comércio internacional. A atividade econômica era, portanto, reduzida a um jogo de soma zero, no qual os ganhos de um país têm lugar em detrimento dos resultados obtidos pelos demais (APPLEYARD; FIELD, 1998).

No final do século XVIII, os chamados autores "clássicos" propuseram um enfoque alternativo com ênfase não mais nos objetivos da nação, mas nas motivações de cada indivíduo (ou 'agente econômico'). A teoria clássica avançou em relação aos mercantilistas, sustentando que para que duas nações negociassem "voluntariamente", ambas deveriam ganhar.

Entre os principais teóricos clássicos estão David Hume (1752), que questionou o argumento mercantilista de que uma economia poderia acumular indefinidamente divisas (ouro) sem afetar, com isso, sua posição competitiva no mercado internacional; Adam Smith (1776), que desenvolveu a Teoria da Vantagem Absoluta, e David Ricardo (1917) ${ }^{5}$, que formulou a Teoria da Vantagem Comparativa.

No final do século XIX e o início do século $X X$, surgiram alguns questionamentos em relação aos supostos básicos da teoria clássica, principalmente no que se refere às diferenças nos custos comparativos, à suposição de custos constantes e ao fato de que os processos produtivos considerassem apenas um fator de produção, o trabalho. Essas e outras indagações levaram à formulação do enfoque neoclássico, fortemente baseado nas relações microeconômicas.

${ }^{5}$ O conceito da vantagem comparativa foi originalmente proposto por David Ricardo em sua publicação The Principles of Political Economy and Taxation, publicada em 1917. 
Os fundamentos básicos da teoria neoclássica enfatizam que as principais fontes de comércio entre os países estão relacionadas às diferenças nas suas dotações de fatores de produção e, não, às diferenças nos processos produtivos, constituindo-se, portanto, uma visão diametralmente oposta à concepção clássica.

A teoria de Heckscher-Ohlin ${ }^{6}$ representa uma das principais contribuições neoclássicas para a teoria do comércio internacional. Essa proposta teórica difere do modelo ricardiano em dois aspectos importantes: primeiro, o modelo ricardiano considera apenas o trabalho como fator de produção, enquanto a teoria de Heckscher-Ohlin leva em consideração também o capital; segundo, essa teoria abandona a questão tecnológica e enfoca as diferenças nas dotações de fatores e a intensidade com que eles são utilizados como a principal fonte de comércio entre os países ${ }^{7}$, admitindo a existência de diferenças tecnológicas entre os produtos, mas não entre os países, como supunha o modelo ricardiano.

Porém, essas formulações teóricas não foram suficientes para explicar a existência de um intenso fluxo de comércio entre países no qual não havia diferenças significativas em relação aos custos e à dotação de fatores, contrariando a teoria das vantagens comparativas.

As primeiras referências a esse tipo de comércio datam do início do século XX, tratadas por Taussig (1947) como uma 'anomalia estatística'. Porém, ele veio a ter um tratamento teórico mais sólido somente a partir da década de 1960, com os trabalhos de Verdoorn (1960); Linder (1961); Balassa (1966) e Grubel (1967). Mas foi apenas com o trabalho conjunto de Grubel e Lloyd (1975) que o tema passou a ter tratamento empírico definitivo ${ }^{8}$.

Nesse contexto, o comércio internacional possibilita que cada país produza uma variedade restrita de bens e obtenha vantagem das economias de escala sem sacrificar a variedade no consumo. A opção de se produzir uma diversidade menor de bens em grande escala provoca ganhos de eficiência, devido às reduções dos custos unitários, aumentos nos lucros e ganhos advindos da complementação industrial entre os países envolvidos.

Se o relaxamento da hipótese de rendimento constante de escala leva à existência de comércio em bases distintas daquelas previstas pela teoria convencional, o mesmo pode ser estabelecido em relação à hipótese de

\footnotetext{
${ }^{6}$ Os princípios básicos dessa teoria, de acordo com Gonçalves et al. (1998), foram formulados originalmente por Eli Filip Heckscher em 1919 e, posteriormente, desenvolvidos por seu ex-aluno, Bertil G. Ohlin, em 1933. Por isso, passou a ser conhecida como teoria ou teorema de Heckscher-Ohlin.

${ }^{7}$ A teoria de Heckscher-Ohlin também é conhecida como a teoria das proporções dos fatores porque enfatiza o mecanismo entre as proporções nas quais fatores diferentes de produção estão disponíveis em países diferentes e as proporções em que esses fatores são utilizados para produzir bens diferentes.

${ }^{8}$ O comércio intra-setorial constitui a Nova Teoria do Comércio Internacional tendo como seus principais representantes Paul Krugman e Elhanam Helpman.
} 
concorrência perfeita. De acordo com Krugman \& Obstfeld (1999), a análise das indústrias caracterizadas por economias de escala, em geral, é feita supondo-se uma estrutura de mercado de concorrência monopolística.

Um outro elemento incluído nessa teoria é a possibilidade de os consumidores terem sua demanda influenciada pela diferenciação dos produtos aparentemente homogêneos, mas que se distinguem por algum atributo específico. Essa diferenciação abre - do ponto de vista do comércio internacional - a possibilidade de intercâmbio de mercadorias entre dois países com exportações e importações simultâneas de produtos normalmente classificados como idênticos.

Porém, a inclusão das hipóteses de economias de escala, diferenciação de produtos e concorrência imperfeita nos modelos de comércio intra-setorial não elimina a possibilidade de existência de comércio intersetorial; na verdade, esses dois tipos de comércio podem ser observados conjuntamente.

De acordo com a literatura especializada, o comércio intra-setorial se mostra mais importante para as nações industrializadas do que para as que estão em processo de desenvolvimento. Porém, à medida que estas nações em desenvolvimento alcançam patamares industriais mais elevados, crescem as oportunidades de diferenciação de bens e, portanto, aumentam, também, a dinâmica de comércio internacional e as oportunidades de internacionalização para empresas nacionais.

Para Fonseca (1989), isso não significa que o comércio intra-setorial está restrito aos países desenvolvidos. A especialização também poderia ocorrer entre países com diferentes níveis de desenvolvimento, quando as variedades de produtos comercializados incorporam atributos correspondentes às suas dotações de fatores.

De forma sucinta, pode-se afirmar que, para a existência do comércio intra-setorial entre duas nações, é necessário que haja especialização, produção em escala e oportunidades de complementação produtiva. Somente a produção de bens diferenciados não é o bastante, pois os ganhos de eficiência, produtividade e competitividade vão ser dados pela escala de produção e não pela simples diferenciação da produção de bens decorrentes da dotação relativa de fatores.

\section{Metodologia}

\subsection{Definições das variáveis e fonte dos dados}

a) Desemprego (DES): a taxa de desemprego expressa o percentual da população economicamente ativa de 10 anos ou mais de idade que se encontra desocupada na semana de referência ${ }^{9}$. Neste estudo, essa

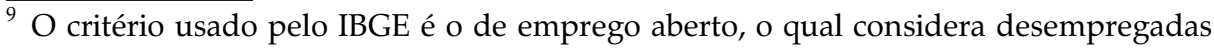
somente aquelas pessoas, que, no período de referência, estavam disponíveis para trabalhar e realmente procuraram trabalho. 
variável foi medida pelas estatísticas da taxa de desemprego ${ }^{10}$ calculadas pelo Instituto Brasileiro de Geografia e Estatística (IBGE) por meio da Pesquisa Nacional por Amostra de Domicílios (PNAD).

b) Abertura Comercial ( $A B R$ ): pode ser definida como o grau de intervenção da política comercial de um país nas suas atividades de exportação e importação. Neste trabalho, o índice de abertura comercial foi calculado pela razão entre a soma do valor das importações e exportações do estado do Ceará pelo seu Produto Interno Bruto (PIB), em cada ano, medidos em US\$ FOB.

c) Índice de Concentração da Pauta de Exportação por Produtos (ICP): representa a relação entre o valor das exportações de um dado produto e o valor total das exportações no t-ésimo período de tempo. O grau de concentração da pauta de exportações cearense foi calculado com base no Índice de Concentração por Produtos (ICP) proposto por Gini-Hirschman.

d) Concentração de Renda $(G)$ : mede o grau de desigualdade existente entre os indivíduos, segundo a renda domiciliar per capita. Neste estudo, foram utilizados os valores do índice de Gini divulgados pela Pesquisa Nacional por Amostra de Domicílios ${ }^{11}$ (PNAD/IBGE), cujos valores variam de zero, quando não há desigualdade, a um, quando a desigualdade é máxima.

e) Grau de Industrialização (GIND): refere-se ao nível de desenvolvimento do parque produtivo e dos processos de produção de uma dada economia. Para mensurar o grau de industrialização do estado do Ceará, foi utilizada a razão entre os valores do PIB das manufaturas ${ }^{12}$ e o PIB total do estado, obtidos junto ao Instituto Brasileiro de Geografia e Estatística (IBGE) e Instituto de Pesquisa Econômica Aplicada (Ipea).

f) Comércio Total (CT): é definido como o fluxo total de mercadorias comercializadas por uma dada economia com o resto do mundo. Esse valor foi obtido pela soma do valor total em US\$ FOB das exportações e importações em cada período de tempo.

g) Comércio Intra-Setorial (CII): definido como o intercâmbio entre dois países com exportações e importações simultâneas de produtos pertencentes a uma mesma indústria. Para medir a intensidade do comércio intra-setorial, foi utilizado o índice proposto por Grubel e Lloyd, (1975), calculado a partir dos valores das exportações e importações de cada produto comercializado internacionalmente.

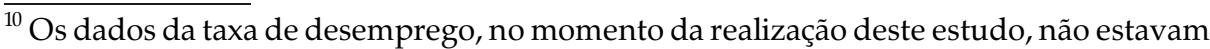
disponíveis para os anos de 2000, 2003 e 2004.

${ }^{11}$ A PNAD não foi realizada para o ano de 2000.

${ }^{12} \mathrm{O}$ PIB das manufaturas refere-se aos produtos incluídos nos grupos 3 ao 14 (ver Quadro 1 do anexo); esse não foi disponibilizado para os anos de 2003 e 2004.
} 
h) Comércio Intersetorial (CEI): é definido como o intercâmbio entre dois países com exportações e importações de produtos pertencentes a indústrias diferentes. Pode ser calculado, de forma residual, pela diferença entre o valor do comércio total (CT) e o valor do comércio intra-setorial (CII).

As informações referentes ao PIB foram obtidas junto ao Instituto Brasileiro de Geografia e Estatística (IBGE), as quais se referem ao valor agregado de todos os bens e serviços finais produzidos dentro do território econômico do País, independentemente da nacionalidade dos proprietários das unidades produtoras desses bens e serviços, excluindo-se as transações intermediárias, isto é, ele é medido a preços de mercados.

As estatísticas sobre as exportações e importações cearenses foram obtidas do banco de dados do sistema Aliceweb disponibilizado pela Secretaria de Comércio Exterior, órgão vinculado ao Ministério do Desenvolvimento, Indústria e Comércio Exterior (Secex/MDIC).

\subsection{Métodos de Análise}

\subsubsection{Determinação do Índice de Comércio Intra-Setorial no estado do Ceará}

Para identificar as categorias de bens que participam do comércio intra-setorial, utilizou-se o índice proposto por Grubel e Lloyd (1975), dado por:

$$
B_{i j t}=\frac{\left(X_{i j t}+M_{i j t}\right)-\left|X_{i j t}-M_{i j t}\right|}{\left(X_{i j t}+M_{i j t}\right)}
$$

no qual:

$X_{i j t}$ representa as exportações da $i$-ésima categoria do estado $j$, em US\$FOB;

$M_{i j t}$ representa as importações da $i$-ésima categoria do estado $j$, em US\$ FOB;

$\left(X_{i j t}+M_{i j t}\right)$ é o comércio total da indústria $i$ do estado $j$;

$\left|X_{i j t}-M_{i j t}\right|$ é o valor absoluto do saldo comercial da indústria $i$ do estado $j$; $t$ representa o $t$-ésimo período de tempo $(t=1, \ldots . ., 9)$.

O índice $B_{i j t}$, descrito acima, está contido no intervalo [0,1]. Quando esse índice assume um valor igual a zero, todo o comércio é feito intersetores. Assim, o comércio é explicado exclusivamente pelas vantagens comparativas. Por outro lado, quando o índice é igual a um, todo o comércio é intra-setorial. Nesse caso, as vantagens comparativas não explicam o comércio, de modo que as economias de escala podem ser uma fonte independente de comércio internacional. 
A medida sumária do comércio intra-setorial, $B_{j t}$, foi obtida por meio da média dos $B_{i j t}$, ponderada pela participação da $i$-ésima categoria no volume total do comércio, $\left(X_{i j t}+M_{i j t}\right) / \sum_{i}\left(X_{i j t}+M_{i j t}\right)$, dada por:

$$
\begin{aligned}
B_{j t}= & \sum_{i} B_{i j t} \frac{\left(X_{i j t}+M_{i j t}\right)}{\sum_{i}\left(X_{i j t}+M_{i j t}\right)}=\sum_{i} \frac{\left(X_{i j t}+M_{i j t}\right)-\left|X_{i j t}-M_{i j t}\right|}{\left(X_{i j t}+M_{i j t}\right)} \cdot \frac{\left(X_{i j t}+M_{i j t}\right)}{\sum_{i}\left(X_{i j t}+M_{i j t}\right)} \\
B_{j t}= & \frac{\sum_{i}\left(X_{i j t}+M_{i j t}\right)-\sum_{i}\left|X_{i j t}-M_{i j t}\right|}{\sum_{i}\left(X_{i j t}+M_{i j t}\right)}
\end{aligned}
$$

De acordo com Grubel e Lloyd (1975), a existência de desequilíbrios entre exportações e importações faz com que os coeficientes $B_{j t}$ sejam viesados no sentido decrescente. Para reduzir os efeitos dos desequilíbrios comerciais agregados, o valor desse índice pode ser expresso por:

$$
C_{j t}=\frac{\sum_{i}\left(X_{i j t}+M_{i j t}\right)-\sum_{i}\left|X_{i j t}-M_{i j t}\right|}{\sum_{i}\left(X_{i j t}+M_{i j t}\right)-\left|\sum_{i} X_{i j t}-\sum_{i} M_{i j t}\right|}
$$

Desse modo, $C_{j t}$ também assume valores compreendidos entre 0 e 1 , cuja interpretação é feita de forma idêntica ao do índice $B_{i j t}$. Para efeitos de ilustração, em termos percentuais, um valor igual a 55 significa que $55 \%$ do comércio se deve à especialização intra-setores e os $45 \%$ restantes podem ser atribuídos ao padrão intersetorial.

Pode-se notar que as fórmulas (2) e (3) apresentam, em seu numerador, a expressão $\sum_{i}\left|X_{i j t}-M_{i j t}\right|$. Assim, para algum subconjunto de categorias, nas quais $X_{i j t} \leq M_{i j t}$ ou $X_{i j t} \geq M_{i j t}$ para todo $i$, tem-se que $\sum\left|X_{i j t}-M_{i j t}\right|=\left|\sum X_{i j t}-\sum M_{i j t}\right|$ para qualquer valor de $X_{i j t}$ e $M_{i j t}$. Nesse caso, desde que uma das restrições seja respeitada, a propriedade da desigualdade dos triângulos $\sum\left|X_{i j t}-M_{i j t}\right|=\sum\left|\sum\left(X_{i j t}-M_{i j t}\right)\right|=\left|\sum X_{i j t}-\sum M_{i j t}\right|$ se verifica como igualdade. Logo, o índice $C_{j t}$ assumirá o valor 1 , uma vez que o numerador se iguala ao denominador. Ademais, o índice $B_{j t}$ tenderá a ser sempre menor que $C_{j t}$, desde que se obedeça às restrições mencionadas. 


\subsubsection{Contribuição do comércio intra-setorial e intersetorial para o crescimento do fluxo comercial cearense}

Para mensurar a contribuição de cada tipo de comércio para a evolução do fluxo total, utilizou-se a abordagem proposta por Menon e Dixon $(1996,1997)$. Considerou-se, inicialmente, que o comércio total (CT) da i-ésima mercadoria no t-ésimo período é dada pela soma do comércio intersetorial (CEI) e do comércio intra-setorial (CII). Assim:

$$
C T_{i j t}=C E I_{i j t}+C I I_{i j t}
$$

sendo que:

$$
\begin{aligned}
& C T_{i j t}=X_{i j t}+M_{i j t} \\
& C E I_{i j t}=\left|X_{i j t}-M_{i j t}\right| \\
& C I I_{i j t}=\left(X_{i j t}+M_{i j t}\right)-\left|X_{i j t}-M_{i j t}\right|
\end{aligned}
$$

Fazendo a diferencial total da equação (4), obtém-se:

$$
\begin{aligned}
& d C T_{i j t}=\frac{\partial C T_{i j t}}{\partial C E I_{i j t}} \cdot d C E I_{i j t}+\frac{\partial C T_{i j t}}{\partial C I I_{i j t}} \cdot d C I I_{i j t} \\
& d C T_{i j t}=d C E I_{i j t}+d C I I_{i j t}
\end{aligned}
$$

Operacionalizando-se algebricamente a equação (8), obtém-se a taxa de crescimento do comércio total, dada por:

$$
\frac{d C T_{i j t}}{C T_{i j t}}=\frac{d C E I_{i j t}}{C E I_{i j t}} \cdot \frac{C E I_{i j t}}{C T_{i j t}}+\frac{d C I I_{i j t}}{C I I_{i j t}} \cdot \frac{C I I_{i j t}}{C T_{i j t}}
$$

Fazendo $\frac{d C T_{i j t}}{C T_{i j t}}=c t_{i j t}, \frac{d C E I_{i j t}}{C E I_{i j t}}=c e i_{i j t}, \frac{d C I I_{i j t}}{C I I_{i j t}}=c i i_{i j t}$ e $B_{i j t}=\frac{C I I_{i j t}}{C T_{i j t}}$, a expressão

(9) pode ser reescrita como:

$$
c t_{i j t}=c e i_{i j t}\left(1-B_{i j t}\right)+c i i_{i j t}\left(B_{i j t}\right)
$$

Na equação (10), $c t_{i j t}, c e i_{i j t}$ e $c i i_{i j t}$ representam, respectivamente, as taxas de crescimento do comércio total, do comércio intersetorial e do comércio intra-setorial em um dado período. 
Considerando que os fatores que determinam o comércio intersetorial são diferentes dos que determinam o comércio intra-setorial, pode-se supor que $c e i_{i j t}$ é determinado independentemente de $c i i_{i j t}$. Então, fazendo $\left(1-B_{i j t}\right) . c e i_{i j t}=C c e i_{i j t} \mathrm{e}$ $B_{i j t} \cdot c i i_{i j t}=C c i i_{i j t}$, a equação (10) pode ser reescrita como:

$$
c t_{i j t}=C_{c e i} i_{i j t}+C_{c i} i_{i j t}
$$

Desta forma, com base na equação (11), podem-se mensurar as contribuições do crescimento do comércio intersetorial (Ccei) e intra-setorial (Ccii) para o crescimento do fluxo de comércio total.

\subsubsection{Indicador de Concentração das Exportações - Coeficiente de Gini-Hirschman}

Para analisar o grau de concentração das exportações em termos de produto, utilizou-se o coeficiente de Gini-Hirschman ${ }^{13}$, também conhecido como o Índice de Concentração por Produto (ICP), estimado por:

$$
I C P_{t}=\sqrt{\sum_{i}\left(\frac{X_{i j t}}{X_{j t}}\right)^{2}}
$$

em que:

$I C P_{t}=$ Índice de Concentração por Produto no $t$-ésimo período;

$X_{j t}=$ valor total das exportações cearenses no $t$-ésimo período.

Esse índice assume valores entre zero e um $(0 \leq I C P \leq 1)$. Um ICP elevado significa que as exportações estão concentradas em poucos produtos. Por outro lado, um baixo índice reflete uma maior diversificação na pauta de exportação.

\subsubsection{Efeitos do comércio intra-setorial e} intersetorial sobre a economia cearense

Para identificar a existência de relação entre os padrões de comércio intra-setorial e intersetorial e as variáveis desemprego, abertura comercial, concentração da pauta de exportação, concentração de renda e grau de industrialização, utilizou-se, a análise de regressão com base no seguinte modelo econométrico:

$$
\ln y_{t}=\beta_{1} \ln C I I_{t}+\beta_{2} \ln C E I_{t}+\varepsilon_{t}
$$

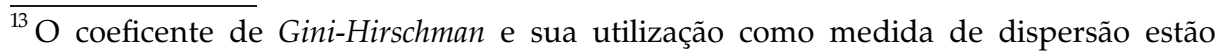
expostos no estudo dos Indicadores do Mercado de Trabalho. Estudos de Economia. IKEI. pág 324. 1996.
} 
No qual $y_{t}$ representa as variáveis: desemprego $(D E S)$, abertura comercial $(A B R)$, concentração da pauta de exportação $(I C P)$, concentração de renda $(G)$ e grau de industrialização (GIND).

A seguir, são apresentados os principais resultados obtidos a partir das metodologias propostas nos itens 3.2.1 a 3.2.4.

\section{Resultados e discussões}

Nesta seção, inicialmente são apresentados os resultados referentes ao dimensionamento, à evolução e à contribuição do comércio intra-setorial para o crescimento do comércio total do Ceará. Posteriormente, analisa-se a relação entre os diferentes padrões de comércio e as principais variáveis econômicas do estado.

\subsection{Dimensionamento do comércio intra-setorial}

Considerando um nível de desagregação de 8 dígitos, nem todos os produtos da pauta de exportação apresentaram simultaneamente valores exportados e importados. A Tabela 1 apresenta a evolução do número de categorias de bens para as quais ocorreu o comércio simultâneo entre mercadorias que pertencem ao mesmo setor.

Nota-se que o número de categorias aumentou aproximadamente $87 \%$ ao longo do período analisado, passando de 144 categorias em 1996 para 269 em 2004. Esse crescimento pode ser explicado, principalmente, pelo aumento da participação dos produtos manufaturados, os quais representam, em média, $90 \%$ das categorias que apresentaram esse padrão de comércio.

Tabela 1. Ceará: número de categorias de bens que apresentaram comércio intra-setorial, 1996 a 2004

\begin{tabular}{cc}
\hline Ano & Categorias selecionadas \\
\hline 1996 & 144 \\
1997 & 148 \\
1998 & 163 \\
1999 & 140 \\
2000 & 160 \\
2001 & 195 \\
2002 & 158 \\
2003 & 193 \\
2004 & 269 \\
\hline
\end{tabular}

Fonte: Elaborada pela autora com base nos dados do Secex/MDIC. 
Para eliminar o viés de estimação do índice de comércio intra-setorial, procurou-se, inicialmente, verificar a existência de desequilíbrios entre as exportações e importações cearenses. Na Tabela 2, estão apresentados os valores totais das exportações e importações, como também os valores totais dos desequilíbrios comerciais das categorias de bens para as quais ocorreu o comércio intra-setorial.

De acordo com os valores apresentados, verifica-se que, nos anos de 1998, 2000 e 2003, ocorreram os mais elevados desequilíbrios comerciais, provocados principalmente por aumentos significativos dos valores exportados, sem que houvesse crescimento da mesma proporção nas importações. De acordo com dados do MDIC (2006), verifica-se que esse aumento pode ser atribuído, principalmente, ao crescimento expressivo das vendas externas de produtos da indústria têxtil, vestuário e calçados, bem como alimentos, fumos e bebidas.

Tabela 2. Ceará: valor total das exportações, importações e desequilíbrios comerciais da economia cearense, considerando as categorias selecionadas, em US\$ FOB

\begin{tabular}{cccc}
\hline Ano & Exportação & Importação & $\begin{array}{c}\text { Desequilíbrios } \\
\text { Comerciais }\end{array}$ \\
\hline 1996 & 120.908 .009 & 36.850 .622 & 84.057 .387 \\
1997 & 91.989 .391 & 42.277 .512 & 49.711 .879 \\
1998 & 190.622 .112 & 19.696 .400 & 170.925 .712 \\
1999 & 77.903 .942 & 21.299 .704 & 56.604 .238 \\
2000 & 293.467 .281 & 67.188 .156 & 226.279 .125 \\
2001 & 110.766 .122 & 127.767 .161 & 17.001 .039 \\
2002 & 54.095 .858 & 15.022 .662 & 39.073 .196 \\
2003 & 130.743 .310 & 14.741 .605 & 116.001 .705 \\
2004 & 99.787 .491 & 45.427 .585 & 54.359 .906 \\
\hline
\end{tabular}

Fonte: Elaborada pela autora com base nos dados do Secex/MDIC.

Devido à existência desses desequilíbrios, os índices de comércio intra-setorial foram calculados a partir de $B_{j t}$ e de $C_{j t}$, cujos valores estão apresentados na Tabela 3. Em todos os anos, o índice de comércio intra-setorial $B_{j t}$ apresentou valores inferiores ao índice $C_{j t}$, ou seja, os coeficientes $B_{j t}$ são viesados no sentido decrescente.

Os maiores vieses ocorreram durante os anos de 1998, 2000 e 2003, devido à existência de elevados desequilíbrios comerciais. Vale destacar que, em alguns períodos, esses desequilíbrios foram tão acentuados que os índices $B_{j t}$ e $C_{j t}$ apresentaram comportamento inverso.

De modo geral, pode-se inferir que grandes desequilíbrios comerciais geram grandes vieses entre os índices $B_{j t}$ e $C_{j t}$. Desse modo, o índice $B_{j t}$ foi utilizado apenas para selecionar as categorias de bens e o índice $C_{j t}$, que expurga os efeitos desses desequilíbrios e, portanto, representa uma medida mais adequada, foi utilizado para medir a intensidade de comércio intra-setorial cearense. 
O comércio intra-setorial e suas implicações para a economia cearense

Tabela 3. Índice de comércio intra-setorial do estado do Ceará ao longo do período de 1996 a 2004, em porcentagem

\begin{tabular}{lccccccccc}
\hline $\begin{array}{l}\text { Indice de comércio } \\
\text { Intra-setorial }\end{array}$ & $\mathbf{1 9 9 6}$ & $\mathbf{1 9 9 7}$ & $\mathbf{1 9 9 8}$ & $\mathbf{1 9 9 9}$ & $\mathbf{2 0 0 0}$ & $\mathbf{2 0 0 1}$ & $\mathbf{2 0 0 2}$ & $\mathbf{2 0 0 3}$ & $\mathbf{2 0 0 4}$ \\
\hline$B_{j t}$ & 17,17 & 15,35 & 6,52 & 12,33 & 5,71 & 5,38 & 9,63 & 3,38 & 6,28 \\
$C_{j t}$ & 36,75 & 24,38 & 34,81 & 28,72 & 15,33 & 5,80 & 22,15 & 16,65 & 10,04 \\
$\left(C_{j t}-B_{j t} / B_{j t}\right)(\%)$ & 114,04 & 58,83 & 433,90 & 132,93 & 168,48 & 7,81 & 130,01 & 392,60 & 59,87 \\
\hline
\end{tabular}

Fonte: Resultado da pesquisa.

Considerando os valores calculados por $\mathrm{C}_{j t}$, apresentados anteriormente na Tabela 3, verifica-se que o comércio intra-setorial responde, em média, por aproximadamente $22 \%$ do comércio total do estado, sendo o restante explicado pelo comércio intersetorial.

Os maiores valores desse índice ocorreram nos anos de 1996, 1998 e 1999. Excetuando-se 1996, esses elevados valores podem ser atribuídos ao crescimento da participação das manufaturas nas exportações cearenses, a qual, em geral, apresentou índices superiores aos obtidos pelos bens primários e minerais, como também uma tendência crescente ao longo do período (Tabela 4).

Esses resultados, portanto, confirmam os pressupostos da teoria do comércio intra-setorial, os quais estabelecem que a maior participação da categoria de bens manufaturados se deve à sua maior capacidade de diferenciação por parte das indústrias.

Tabela 4. Participação do comércio de manufaturas e bens primários e minerais em relação ao comércio intra-setorial durante o período de 1996 a 2004, em percentagem

\begin{tabular}{|c|c|c|c|c|c|c|c|c|c|}
\hline Produtos & 1996 & 1997 & 1998 & 1999 & 2000 & 2001 & 2002 & 2003 & 2004 \\
\hline $\begin{array}{l}\text { Produtos } \\
\text { Manufaturados }\end{array}$ & 23,34 & 77,62 & 84,38 & 91,81 & 93,80 & 87,80 & 87,87 & 88,92 & 91,46 \\
\hline $\begin{array}{l}\text { Bens Primários e } \\
\text { Produtos Minerais }\end{array}$ & 76,66 & 22,38 & 15,62 & 8,19 & 6,20 & 12,20 & 12,13 & 11,08 & 8,57 \\
\hline
\end{tabular}

Fonte: Resultado da pesquisa.

\subsection{Composição do comércio intra-setorial por fator agregado}

A Tabela 5 apresenta o valor do comércio intra-setorial para os bens manufaturados, primários e minerais. Com base nesses dados, constata-se que, apesar das manufaturas apresentarem uma tendência crescente em termos de valor, o comércio intra-setorial total apresentou uma tendência decrescente, explicada, principalmente, pela redução média anual de $21,49 \%$ no comércio de produtos primários e minerais.

Após um período de retração no comércio exterior, o ano de 2000 foi marcado por uma evolução nas exportações e importações cearenses. Esse fato ocorreu 
devido, principalmente, às mudanças na política de promoções das exportações, à entrada de firmas estrangeiras, à adoção de novas estratégias de inserção no mercado das firmas que já atuam no exterior e, ainda, à desvalorização do Real em relação à moeda norte-americana.

De acordo com dados do Ipece (2004), entre 1998 e 2004, foram instaladas, em território cearense, aproximadamente 1.852 indústrias. O programa estadual de atração de investimentos, iniciado em 1990, também teve uma importante contribuição para um melhor desempenho das indústrias. Entre os segmentos beneficiados com esses incentivos destacam-se: têxtil, couro-calçadista, produtos alimentares e bebidas.

Tabela 5. Ceará: comércio intra-setorial total das manufaturas e dos bens primários e minerais

\begin{tabular}{|c|c|c|c|c|c|c|}
\hline \multirow[b]{2}{*}{ Ano } & \multicolumn{2}{|c|}{$\begin{array}{c}\text { Bens Primários } \\
\text { e Minerais }\end{array}$} & \multicolumn{2}{|c|}{$\begin{array}{c}\text { Produtos } \\
\text { Manufaturados }\end{array}$} & \multicolumn{2}{|c|}{$\begin{array}{c}\text { Comércio } \\
\text { Intra-Setorial Total }\end{array}$} \\
\hline & US\$ FOB & $\begin{array}{c}\text { Taxa de } \\
\text { Crescimento } \\
\%\end{array}$ & US\$ FOB & $\begin{array}{c}\text { Taxa de } \\
\text { Crescimento } \\
\%\end{array}$ & US\$ FOB & $\begin{array}{c}\text { Taxa de } \\
\text { Crescimento } \\
\%\end{array}$ \\
\hline 1996 & 20.762 .638 & & 6.319 .936 & & 27.082 .574 & \\
\hline 1997 & 4.612 .764 & $-77,78$ & 16.000 .960 & 153,18 & 20.613 .724 & $-23,89$ \\
\hline 1998 & 2.142 .564 & $-53,55$ & 11.571 .562 & $-27,68$ & 13.714 .126 & $-33,47$ \\
\hline 1999 & 1.002 .096 & $-53,23$ & 11.231 .018 & $-2,94$ & 12.233 .114 & $-10,80$ \\
\hline 2000 & 1.275 .950 & 27,33 & 19.319 .438 & 72,02 & 20.595 .388 & 68,36 \\
\hline 2001 & 1.566 .546 & 22,77 & 11.277 .010 & $-41,63$ & 12.843 .556 & $-37,64$ \\
\hline 2002 & 807.136 & $-48,48$ & 5.848 .754 & $-48,14$ & 6.655 .890 & $-48,18$ \\
\hline 2003 & 544.122 & $-32,59$ & 4.366 .222 & $-25,35$ & 4.910 .344 & $-26,23$ \\
\hline 2004 & 781.310 & 43,59 & 8.337.978 & 90,97 & 9.119.288 & 85,72 \\
\hline Média & & $-21,49$ & & 21,30 & & $-3,27$ \\
\hline
\end{tabular}

Fonte: Elaborada pela autora com base nos dados do Secex/MDIC.

O processo de industrialização também foi fortemente influenciado pela implantação do Plano Real em 1994. A valorização cambial e a estabilização de preços da economia incentivaram as importações de máquinas e equipamentos necessários à modernização do parque industrial do estado, aumentando sua capacidade produtiva (RACY, 2006).

A Tabela 6 apresenta os principais grupos de produtos responsáveis pelas variações no comércio intra-setorial ${ }^{14}$. Com base nos valores apresentados, verifica-se que os produtos "Têxtil, Vestuário e Calçados”, "Alimentos, Fumo e Bebidas", "Máquinas e Equipamentos" e "Couros e Peles" apresentaram as maiores participações.

\footnotetext{
${ }^{14}$ Os grupos "Alimentos, Fumo e Bebidas" e "Minerais" representam os bens primários e minerais, enquanto os demais grupos representam os produtos manufaturados.
} 
Em relação a esses produtos, pode-se afirmar que eles estão incluídos nos setores que requerem relativamente um baixo conteúdo tecnológico; são intensivos em mão-de-obra e recursos naturais e, portanto, apresentam baixo valor agregado, contrariando o que a teoria sugere, ou seja, que o comércio intra-setorial deveria ser mais intensivo para os produtos que requerem mais tecnologia.

Desse modo, a elevada participação desses grupos indica que as economias de escala e a diferenciação dos produtos são os principais fatores que explicam o seu comércio. Desse modo, essas indústrias podem se beneficiar com a intensificação dos acordos de integração comercial devido ao aumento do tamanho do mercado.

Por outro lado, os grupos com as menores participações foram: "Madeira e Carvão Vegetal", "Papel e Celulose" e "Material de Transporte", indicando que, para esses produtos, o comércio é explicado essencialmente por diferenças nas dotações de fatores entre o estado e seus parceiros comerciais.

Para essas indústrias, ao contrário do que foi observado anteriormente, um maior grau de abertura pode ter efeitos adversos sobre os fatores de produção nelas intensivamente empregados. Haverá também uma probabilidade mais elevada de imposição de barreiras comerciais devido à necessidade de, em alguns casos, impor limites à concorrência estrangeira.

Tabela 6. Ceará: participação percentual dos grupos de produtos no comércio intra-setorial, 1996 a 2004

\begin{tabular}{lccccccccc}
\hline Grupos & $\mathbf{1 9 9 6}$ & $\mathbf{1 9 9 7}$ & $\mathbf{1 9 9 8}$ & $\mathbf{1 9 9 9}$ & $\mathbf{2 0 0 0}$ & $\mathbf{2 0 0 1}$ & $\mathbf{2 0 0 2}$ & $\mathbf{2 0 0 3}$ & $\mathbf{2 0 0 4}$ \\
\hline Alimentos, Fumo e Bebidas & $\mathbf{7 6 , 5 4}$ & 22,26 & $\mathbf{1 5 , 2 3}$ & $\mathbf{8 , 1 9}$ & 5,89 & 11,87 & 11,12 & 10,30 & 8,21 \\
Minerais & 0,13 & 0,12 & 0,40 & 0,00 & 0,30 & 0,32 & 1,00 & 0,78 & 0,36 \\
Produtos Químicos & 0,09 & 0,02 & 0,07 & 0,10 & 1,17 & 0,47 & 0,13 & 0,29 & 0,93 \\
Plásticos e Borracha & 0,46 & 0,10 & 2,22 & 0,18 & 0,03 & 0,42 & 3,17 & 4,88 & 2,40 \\
Couros e Peles & 0,14 & 0,96 & 0,05 & 12,46 & 46,36 & 21,88 & 24,83 & 3,02 & 3,67 \\
Madeira e Carvão Vegetal & 0,04 & 0,14 & 0,40 & 0,21 & 0,08 & 0,10 & 0,08 & 0,48 & 0,04 \\
Papel e Celulose & 0,00 & 0,00 & 0,03 & 0,07 & 0,01 & 0,14 & 0,11 & 0,59 & 0,70 \\
Têxtil, Vestuário e Calçados & 15,42 & 60,37 & 68,47 & 68,67 & 32,09 & 41,48 & 36,11 & 54,50 & 40,89 \\
Minerais não Metálicos & 0,64 & 0,25 & 0,74 & 0,34 & 0,07 & 0,27 & 1,71 & 3,48 & 7,39 \\
Metais Comuns & 0,15 & 5,18 & 2,74 & 0,91 & 3,30 & 2,24 & 3,35 & 2,00 & 2,42 \\
Máquinas e Equipamentos & 5,36 & 9,43 & 7,22 & 7,22 & 9,59 & 19,71 & 17,81 & 17,05 & 30,05 \\
Material de Transporte & 0,34 & 0,12 & 0,14 & 0,14 & 0,36 & 0,17 & 0,08 & 0,36 & 0,59 \\
Ótica e Instrumentos & 0,62 & 0,82 & 0,82 & 0,29 & 0,61 & 0,74 & 0,19 & 0,60 & 1,72 \\
Outros & 0,07 & 0,25 & 1,48 & 1,22 & 0,14 & 0,20 & 0,29 & 1,67 & 0,62 \\
Total & 100 & 100 & 100 & 100 & 100 & 100 & 100 & 100 & 100 \\
\hline
\end{tabular}

Fonte: Resultado da pesquisa.

A análise desenvolvida até aqui mostrou a participação e a evolução do comércio intra-setorial no Ceará. A seguir, procura-se mensurar a sua contribuição para o crescimento do fluxo de comércio total do estado. 


\subsection{Contribuição do comércio intra-setorial e intersetorial para o crescimento do fluxo de comércio}

Apesar dos ganhos de participação das manufaturas, o valor do comércio intra-setorial total apresentou um grande declínio ao longo do período analisado. Por outro lado, o comércio intersetorial cresceu, passando a representar, em média, aproximadamente $98 \%$ do valor total comercializado, chegando a mais de 99\% entre 2002 e 2004 (Tabela 7).

Equacionando essas perdas e ganhos, verifica-se, como resultado final, um considerável aumento no comércio total. O maior crescimento ocorreu entre 1999 e 2000 com uma variação em torno de $28 \%$, impulsionada, dentre outros fatores, pelo crescimento das exportações devido, principalmente, à desvalorização da moeda nacional em relação ao dólar.

Desse modo, pode-se inferir que, apesar da importância das economias de escala no comércio internacional, as vantagens comparativas ainda se apresentam como a principal fonte de comércio para o Ceará.

De acordo com Ohlin (1968), o comércio intra-setorial representa uma fonte adicional de comércio, porém, sua importância não supera o comércio intersetorial. Para Baumann et al. (2004), a importância relativa de cada um depende do grau de similaridade entre os parceiros comercias, principalmente, no que diz respeito à razão capital-trabalho, à qualificação da mão-de-obra e ao grau de desenvolvimento econômico. Se estes são muito diferentes, haverá predomínio do comércio intersetorial, pois cada um obterá vantagens em produzir os bens cujas tecnologias requerem a utilização intensiva do fator relativamente mais abundante.

Tabela 7. Ceará: participação do comércio intra-setorial e intersetorial no valor total de comércio

\begin{tabular}{cccccc}
\hline \multirow{2}{*}{ Ano } & \multicolumn{2}{c}{ CII } & \multicolumn{2}{c}{ CEI } & CT \\
\cline { 2 - 6 } & US\$ FOB & $\%$ & US\$ FOB & $\%$ & US\$ FOB \\
\hline 1996 & 27.082 .574 & 2,27 & 1.166 .820 .631 & 97,73 & 1.193 .903 .205 \\
1997 & 20.613 .724 & 1,99 & 1.014 .367 .421 & 98,01 & 1.034 .981 .145 \\
1998 & 13.714 .126 & 1,43 & 947.475 .223 & 98,57 & 961.189 .349 \\
1999 & 12.233 .114 & 1,29 & 932.447 .756 & 98,71 & 944.680 .870 \\
2000 & 20.595 .388 & 1,70 & 1.192 .435 .481 & 98,30 & 1.213 .030 .869 \\
2001 & 12.843 .556 & 1,12 & 1.137 .699 .181 & 98,88 & 1.150 .542 .737 \\
2002 & 6.655 .890 & 0,56 & 1.173 .156 .164 & 99,44 & 1.179 .812 .054 \\
2003 & 4.910 .344 & 0,38 & 1.296 .792 .902 & 99,62 & 1.301 .703 .246 \\
2004 & 9.119 .288 & 0,64 & 1.423 .845 .575 & 99,36 & 1.432 .964 .863 \\
\hline Média & \multicolumn{5}{c}{} \\
\hline
\end{tabular}

Fonte: Elaborada pela autora com base nos dados do Secex/MDIC.

Para um melhor entendimento do padrão de intercâmbio internacional dos produtos cearenses, devem ser considerados, ainda, os principais países de destinos e origens dessas mercadorias. De acordo com dados do MDIC (2006), as exportações 
estão concentradas em apenas oito países de destino, os quais demandam, em média, $74 \%$ do valor total ${ }^{15}$. Somente os Estados Unidos adquirem, em média, aproximadamente $47 \%$ do valor total. Por outro lado, em torno de $70 \%$ do valor das importações concentram-se em dez países, sendo que os Estados Unidos, a Argentina e a Venezuela respondem, em média, por $47 \%$ desse valor.

A elevada participação dos Estados Unidos, tanto nas exportações quanto nas importações, é uma das principais evidências que dão suporte à maior importância do comércio intersetorial no intercâmbio internacional cearense de mercadorias. Isso porque as acentuadas diferenças nas dotações dos fatores, nos níveis tecnológicos e no desenvolvimento econômico providenciam um suporte analítico adequado para justificar as vantagens comparativas como principal fonte de comércio.

Analisando a Tabela 8, verifica-se que, em todos os anos, a contribuição do comércio intra-setorial ainda é relativamente pouco expressiva. Por outro lado, o comércio intersetorial apresentou uma participação positiva de 3,19\%, levando a um crescimento médio de $3,01 \%$ no fluxo total, podendo-se inferir que as vantagens comparativas ainda representam um importante fator para $\mathrm{o}$ desenvolvimento do comércio no estado.

Apesar da pequena participação do comércio intra-setorial no crescimento do fluxo do comércio total do estado, espera-se que este possa trazer benefícios para a economia cearense. Desse modo, a seguir, procura-se verificar a relação entre a evolução do comércio intra e intersetorial, sobre as principais variáveis econômicas, a fim de compreender, com maior clareza, as suas implicações para o crescimento e desenvolvimento do Ceará.

Tabela 8. Contribuição do comércio intra-setorial e intersetorial para o crescimento do fluxo comercial total do estado do Ceará $(\%)^{16}$

\begin{tabular}{cccc}
\hline Anos & ct & Ccii & Ccei \\
\hline $96 / 97$ & $-13,31$ & $-0,54$ & $-12,77$ \\
$97 / 98$ & $-7,13$ & $-0,67$ & $-6,46$ \\
$98 / 99$ & $-1,72$ & $-0,15$ & $-1,56$ \\
$99 / 00$ & 28,41 & 0,89 & 27,52 \\
$00 / 01$ & $-5,15$ & $-0,64$ & $-4,51$ \\
$01 / 02$ & 2,54 & $-0,54$ & 3,08 \\
$02 / 03$ & 10,33 & $-0,15$ & 10,48 \\
$03 / 04$ & 10,08 & 0,32 & 9,76 \\
\hline Média & 3,01 & $-0,18$ & 3,19 \\
\hline
\end{tabular}

Fonte: Resultado da pesquisa.

\footnotetext{
${ }^{15}$ Os oito principais países de destino das exportações cearenses, em termos de participação percentual média, entre 1996 e 2004, em ordem decrescente de importância, foram: Estados Unidos, Argentina, Itália, Canadá, Países Baixos (Holanda), Paraguai, Espanha e Japão. Em relação às importações, os principais países foram: Argentina, Estados Unidos, Venezuela, Alemanha, Itália, Japão, China, Canadá, Uzbequistão, Taiwan. (MDIC, 2006).

${ }^{16}$ Estimados a partir da equação (10).
} 


\subsection{Relação entre o comércio e as principais variáveis macroeconômicas}

Com base nos resultados da análise de regressão ${ }^{17}$, expostos na Tabela 9, verifica-se que, para o conjunto das variáveis analisadas, o comércio intra-setorial e intersetorial não apresentaram efeitos estatisticamente significativos apenas sobre o grau de industrialização.

\section{Desemprego}

Os incrementos nos fluxos de comércio intra-setorial e intersetorial têm efeitos diferentes sobre o desemprego, ou seja, o aumento do comércio intra-setorial reduz o desemprego, enquanto um acréscimo no comércio intersetorial, implicaria em um aumento na taxa de desemprego.

Tabela 9. Efeitos entre o valor do comércio intra-setorial e intersetorial e as variáveis econômicas, 1996 a 2004

\begin{tabular}{llcccc}
\hline Variáveis Econômicas & Intra-setorial & Intersetorial & $\mathbf{R}^{\mathbf{2}}$ & $\mathbf{R}^{\mathbf{2}}$ ajustado \\
\hline \multirow{2}{*}{ Desemprego } & Coeficiente & $-0,304^{* *}$ & $0,33^{*}$ & $81,24 \%$ & $76,55 \%$ \\
& Erro padrão & 0,082 & 0,064 & & \\
& $\mathrm{~N}$ & 6 & 6 & & \\
\hline \multirow{2}{*}{ Abertura } & Coeficiente & $-0,434^{* *}$ & $0,23^{* * *}$ & $51,25 \%$ & $44,29 \%$ \\
Comercial & Erro padrão & 0,125 & 0,097 & & \\
\hline Concentração & $\mathrm{N}$ & 9 & 9 & & \\
da Pauta de & Erro padrão & 0,057 & 0,045 & & $75,59 \%$ \\
Exportação & $\mathrm{N}$ & 9 & 9 & & \\
\hline \multirow{2}{*}{ Concentração } & Coeficiente & $0,055^{*}$ & $-0,067^{*}$ & $93,4 \%$ & $92,3 \%$ \\
de Renda & Erro padrão & 0,005 & 0,004 & & \\
& $\mathrm{~N}$ & 8 & 8 & & \\
\hline \multirow{2}{*}{ Grau de } & Coeficiente & $-0,017$ & $-0,036$ & $17,73 \%$ & $1,28 \%$ \\
Industrialização & Erro padrão & 0,044 & 0,034 & & \\
& $\mathrm{~N}$ & 7 & 7 & & \\
\hline
\end{tabular}

Fonte: Resultado da pesquisa

Nota: Os símbolos ${ }^{* *} \mathrm{e}^{* * *}$ indicam que os coeficientes de correlação são significantes a $1 \%, 5 \%$ e $10 \%$, respectivamente.

De acordo com Baumann et al. (2004), os efeitos do comércio intra-setorial sobre o desemprego podem ser explicados, principalmente, pelos seus reduzidos "custos de ajuste". Ao contrário do que ocorre com o comércio intersetorial, o

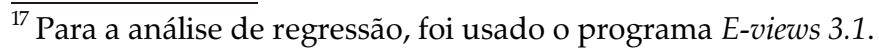


fator desempregado por uma empresa pode ser absorvido por outras em um período de tempo mais curto e com menores custos de treinamento, desde que, dentro de um mesmo setor de atividade, o tipo de capacitação exigida seja similar.

No entanto, analisando os dados da Pesquisa Nacional por Amostra de Domicílios (PNAD), entre 1999 e 2001, verifica-se que, apesar dos aumentos nos valores comercializados internacionalmente, tanto intra quanto intersetorialmente, ocorreu um aumento na taxa de desemprego. Para Gremaud et al. (2002), esse aumento pode ser explicado, dentre outros fatores, pela intensificação do processo de abertura comercial ocorrido na década de 1990, associada à reduzida competitividade da indústria nacional, o qual, por um lado, estimulou a entrada de muitos produtos importados e, por outro, provocou o fechamento de um grande número de empresas em todo o País.

Para Markwald (2001), os efeitos esperados em relação à intensificação do processo de abertura comercial sobre o emprego nesse período eram positivos. Projetava-se que os mais elevados níveis de exportações combinados com a alocação mais eficiente dos recursos produtivos, devido à remoção de distorções promovidas pelo modelo de industrialização em vigor, poderiam acelerar o crescimento da produção e expandir a demanda por empregos. Porém, o que ocorreu de fato foi que a elevada pressão competitiva levou o setor industrial a adotar novos métodos de produção com menores custos e tecnologias poupadoras de mão-de-obra, contribuindo para uma elevada contração da demanda por mão-de-obra.

\section{Abertura comercial}

Ao contrário do que sugere a nova teoria de comércio internacional ${ }^{18}$ para o Ceará, um aumento no comércio intra-setorial pode reduzir o grau de abertura comercial, enquanto essa mesma variação no comércio intersetorial pode aumentá-la.

Para Viana (2005), as dificuldades de inserção dos estados nordestinos, exportadores de produtos intensivos em recursos naturais, trabalho e que possuem reduzido valor agregado, estão associadas, principalmente, às imposições de exigências qualitativas por parte dos países desenvolvidos, exportadores de manufaturas.

\footnotetext{
${ }^{18}$ De acordo com a nova teoria de comércio internacional, a intensificação do comércio intra-setorial apresenta uma relação direta com a abertura comercial devido à necessidade de complementação dos processos produtivos entre os parceiros comerciais (BAUMANN et al., 2004).
} 


\section{Concentração da pauta de exportação}

Os incrementos nos valores do comércio intra-setorial e intersetorial têm efeitos opostos sobre a pauta de exportações, sendo que o primeiro atua no sentido de concentrá-la, enquanto o segundo aumenta o número de categorias de bens comercializados internacionalmente.

Esses efeitos trazem em si alguns aspectos importantes: primeiro, a indústria cearense pode obter vantagens a partir das economias de escalas, especializando-se na produção em uma pequena variedade de bens; segundo, para que esse processo ocorra de forma satisfatória, é necessário que as políticas de inserção comercial considerem as diferenças nas dotações relativas de fatores entre seus parceiros, pois quanto maiores forem essas discrepâncias, mais acentuada será a importância das vantagens comparativas como fonte de comércio.

Para Muendler (2001), o aumento da competição externa teve um importante impacto sobre o desempenho da produtividade da indústria brasileira, contribuindo para eliminar as empresas cujos processos produtivos apresentavam elevado grau de ineficiência. Adicionalmente, Neto e de Paula (2001) afirmam que, a sobrevalorização da moeda nacional incentivou as importações, de modo que, para manter-se no mercado, a indústria local teve que promover mudanças significativas em seus produtos e serviços, levando a melhorias na variedade e qualidade dos produtos.

Para Markwald (2001), a abertura comercial, além de desempenhar um papel fundamental no sentido de desobstruir o intercâmbio de mercadorias, facilitou, também, o fluxo de idéias e tecnologias, contribuindo para a inovação de produtos, para a especialização produtiva e para o aumento das escalas de produção.

\section{Índice de Gini}

De acordo com dados do Instituto de Pesquisa Econômica Aplicada (Ipea), verifica-se que entre 1996 e 2004, o Ceará apresentou um índice de concentração de renda relativamente elevado, porém com uma tendência decrescente. No entanto, os resultados obtidos mostram que o crescimento no comércio intra-setorial pode elevar o nível de concentração de renda, enquanto a intensificação do comércio intersetorial atua no sentido de distribuí-la de forma mais igualitária.

Embora a relação direta entre o índice de concentração de renda e o de comércio intra-setorial contrarie a teoria, a qual afirma que uma expansão no comércio intra-setorial resultaria em uma queda na concentração de renda, deve-se considerar que seus efeitos estão diretamente associados às características dos bens comercializados e ao requerimento de fatores utilizados na sua produção. 
Os índices de comércio intra-setorial, analisados anteriormente, evidenciam a importância relativa das manufaturas nesse tipo de transação. Embora no Ceará as mercadorias comercializadas sejam caracterizadas como manufaturas de baixo valor agregado, considerando-se o conjunto total de produtos exportados, elas requerem relativamente mais capital e mão-de-obra qualificada, fatores que são relativamente escassos no estado.

Desse modo, um crescimento da participação dessas mercadorias na pauta de exportações deixaria os proprietários desses fatores, que representam uma pequena parcela da população, em melhores condições que os demais, elevando o grau de concentração de renda no Ceará.

Porém, deve-se salientar que, como afirma Krugman e Obstfelds (1999), as mudanças na distribuição de renda não são efeitos específicos do comércio, visto que todas as alterações na economia, provocadas por avanços tecnológicos, mudanças nas preferências, disponibilidades de recursos produtivos, entre outras, também exercem efeitos relevantes sobre essa variável.

Em suma, pode-se afirmar que os padrões de comércio intra e intersetorial apresentam diferentes efeitos sobre o desenvolvimento do Ceará. Dentro desse contexto, faz-se necessário direcionar as políticas de incentivo aos diferentes setores exportadores de forma compatível com os objetivos a serem atingidos em termos de crescimento econômico e bem-estar dos agentes envolvidos.

\section{Conclusões}

Neste estudo, procurou-se analisar a participação do comércio intra-setorial no fluxo total de comércio no Ceará e avaliar seus efeitos sobre importantes variáveis macroeconômicas. Com base nos resultados obtidos, pode-se concluir que a participação do comércio intra-setorial ainda é pouco expressiva, apresentando tendência decrescente ao longo do período analisado. O principal fator responsável por essa tendência foi a redução do comércio de produtos primários e minerais.

O número de categorias de bens que participam do comércio intra-setorial apresentou um grande crescimento entre 1996 e 2004. Em termos de grupos, os produtos com maiores participações foram: "Têxtil, Vestuário e Calçados"; "Alimentos, Fumo e Bebidas" e "Couros e Peles", caracterizados como manufaturas de baixo valor agregado, com exceção de alguns produtos do grupo "Alimentos, Fumo e Bebidas". A elevada participação desses grupos indica que as economias de escala e a diferenciação dos produtos são importantes fatores para o crescimento desses setores de atividades.

Apesar da importância das economias de escala para esses grupos de produtos, as vantagens comparativas ainda se apresentam como a principal fonte de comércio para o Ceará devido principalmente às acentuadas diferenças 
nas dotações dos fatores, nos níveis tecnológicos e no desenvolvimento econômico entre o estado e seus principais parceiros comerciais.

Em relação à influência do comércio sobre o crescimento da economia cearense, verificou-se que os padrões intra e intersetorial têm efeitos opostos e significativos sobre as principais variáveis consideradas, exceto sobre o grau de industrialização. Esses efeitos, no entanto, não estão totalmente de acordo com as hipóteses estabelecidas inicialmente.

A intensificação do comércio intra-setorial traz os seguintes impactos: redução da taxa de desemprego e do grau de abertura da economia; aumento do índice de concentração da pauta de exportações e do nível de concentração de renda. Por outro lado, um aumento do comércio intersetorial pode aumentar a taxa de desemprego e o grau de abertura da economia e diminuir o grau de concentração da pauta de exportações e os índices de concentração de renda.

O aumento do índice de concentração da pauta de exportações, resultante dos incrementos nos valores do comércio intra-setorial, indica que a indústria cearense pode obter vantagens a partir das economias de escalas, especializando-se na produção em uma pequena variedade de bens.

Porém, para que se possam obter maiores benefícios com essa especialização, os processos de inserção comercial adotados pelo estado deverão considerar as diferenças nas dotações relativas de fatores entre seus parceiros comerciais, pois quanto maiores forem essas diferenças, mais importantes serão as vantagens comparativas como fonte de comércio.

\section{Referências Bibliográficas}

ALBUQUERQUE, C. R. e FERNANDES, C. L. L. Impactos da liberação comercial no perfil do comércio exterior brasileiro. In: Anais. Belém. ANPEC (em CD-ROM), 1999.

APPLEYARD, D. e FIELD, A. International Economics: Trade Theory and Policy. Cingapura: McGraw-Hill, 1998.

BALASSA, B. "Tariff reductions and trade in manufactures among industrial countries". American Economics Reviews, v. 56, n. 3, 1966.

BAUMANN, R. Nota sobre as relações intra-setoriais no comércio externo brasileiro - 1980-1996. Revista Cepal. Escritório no Brasil, 1998.

BAUMANN, R.; CANUTO, O.; GONÇALVES, R. Economia Internacional: teoria e experiência brasileira. Rio de janeiro: Elsevier, 2004. 422p

FONSECA, R da. Teoria de comércio intra-indústria: uma nova teoria de comércio internacional. Literatura Econômica. v.11, n.3, p. 679-694, out.1989. 
. Comércio Intra-Indústria e Integração. RBCE,n.23, maio/jun 1989.

GONÇALVES, R.; BAUMANN, R.; CANUTO, O.; PRADO, L.C.D. A nova economia internacional: uma perspectiva brasileira. 5.ed. Rio de Janeiro: Campos, 1998. 392p.

GREMAUD, A. P., SAES, F. A. M; TONETO JÚNIOR, R. Formação Economia do Brasil, São Paulo, Atlas, 2002.

GRUBEL, H.G. "Intra-Industry specialization and the pattern of trade". Canadian Journal of Economics and Political Science, v.33, 1967.

. e LLOYD, P. J. Intra-Industry Trade: The Theory and Measurement of International Trade in Differentiated Products. Londres, MacMillan Press, 1975.

HIDALGO, A. B. O intercâmbio comercial brasileiro intra-indústria: Uma análise entre indústrias e entre países. Revista Brasileira de Economia, v.47, n. 2. p. 243-264, 1993.

Especialização e Competitividade do Nordeste no Mercado Internacional. Revista Econômica do Nordeste. Fortaleza, v. 19, n. especial, p.491-515, jun, 1998.

INSTITUTO BRASILEIRO DE GEOGRAFIA E ESTATÍSTICA - IBGE. Indicadores econômicos. Disponível em : < https://www.sidra.ibge.gov.br $>$. Vários acessos.

INSTITUTO DE PESQUISA ECONÔMICA APLICADA - IPEADATA. Indicadores econômicos. Disponível em : < https://www.ipeadata.gov.br $>$. Vários acessos.

INSTITUTO DE PESQUISA E ESTRATÉGIA ECONÔMICA DO CEARÁ-IPECE. Informativos. Disponível em: $<$ http//www.ipece.ce.gov.br $>$. Vários acessos.

KRUGMAN, P. R. e OBSTFELDS, M. Economia Internacional: teoria e política. 5. ed. São Paulo: Makron Books, 1999.

LERDA, S. C. M. S. Comércio internacional intra-indústria: Aspectos teóricos e algumas evidências, $\mathrm{cm}$ aplicação ao caso brasileiro. Dissertação de mestrado. Universidade de Brasília. 1988.

LINDER, S. B. Na Essay on Trade and Transformation. Nova York: Wiley, 1961.

MARKWALD, R. A. O impacto da abertura comercial sobre a indústria brasileira: balanço de uma década. Revista Brasileira de Comércio Exterior, n. 68, julho-setembro: 04-25. 2001. 
MENON, J. e DIXON, P. B. Regional trading agreements and intra-industry trade. Journal of Economics Integration, v.11, n.1, p. 1-20, 1996.

. Measures of intra-industry trade as indicators of factor market disruption. The Economics Records, 73 (222): 233-247, 1997.

MINISTÉRIO DO DESENVOLVIMENTO, INDÚSTRIA E COMÉRCIO EXTERIOR -

MDIC - Secretaria de Comércio Exterior - SECEX. Exportações. Disponível em: $<\underline{\text { https://www.mdic.gov.br }}>$. Vários acessos.

. Secretaria de Comércio Exterior - SECEX. Importações. Disponível em: < https://www.mdic.gov.br $>$. Vários acessos.

MUENDLER, M. A. Trade, Technology, and Productivity: A Study of Brazilian Manufacturers, 1986-98. University of California, Berkeley e PUC/RJ, maio, 2001.

NETO, F.J. da C. e de PAULA, D.B.A. A Influência do Plano na Postura Estratégica das ME e EPP no estado do Ceará. In: Anais do I Encontro de Pós-Graduação e Pesquisa, pág 424-429, Abril/2001.

OHLIN, B. Interregional and international trade. Cambridge, Mass.: Harvard University, 1968.

OLIVEIRA, M. H. Evidências empíricas do comércio intra-indústria. Revista Brasileira de Economia, v.40, n. 33, p. 211-232, 1986.

RACY, J. C. Introdução à gestão de negócios internacionais. São Paulo: Pioneira Thomson Learning, 2006.

RICARDO, D. The Principles of Political Economy and Taxation. Homewood, IL: Irwin, 1963.

SMITH, A. The Wealth of Nations. Chicago: The University of Chicago Press, 1776.

TAUSSIG, F. W. Principles of economics. Nova York: Macmillan, 1947.

VERDOORN, J. P. "The intra-bloc trade of Benelux". In: ROBINSON, E. A. G., (org.). Economics consequences of the size of nations. Londres: Macmillan, 1960.

VIANA, F. D. F.; XAVIER, C. L. Competitividade e Desempenho Externo dos Estados da Região Nordeste do Brasil no Período 1995-2004. Revista Econômica do Nordeste, 2005. 